\title{
Smartphone Habits and Behaviors in Supporting Students Self-Efficacy
}

\author{
https://doi.org/10.3991/ijet.v13i02.7685 \\ Abdur Razzaq, Yulia Tri Samiha \\ Universitas Islam Negeri Raden Fatah, Palembang, Indonesia \\ Muhammad Anshari $\left.{ }^{\bowtie}\right)$ \\ Universiti Brunei Darussalam, Brunei Darussalam \\ anshari.ali@ubd.edu.bn
}

\begin{abstract}
The widespread of smartphones usage have increased the convenience of accessing information and knowledge sharing for higher learning students. University's students are exposed with the multi channels of knowledge from various sources primarily from online learning's resources. The study examines smartphone habit and behaviors, internet literacy, and mobile learning in relation to self-efficacy. Self-efficacy refers to the internal forces of a student's belief in the abilities in utilizing smartphone as educational aid in the context of mobile learning. This study deploys a quantitative approach in assessing the relationship between self-efficacy, internet literacy and smartphone's habits for of university students. Understanding student selfefficacy is important factor to deliver an effective ways in supporting mobile learning activities. In addition to documenting the findings of self-efficacy and mobile learning, the research also represents a model of internal and external factors that affects student self-efficacy to make mobile learning successful.
\end{abstract}

Keywords-Internet literacy, Mobile learning, Smartphone Habits, SelfEfficacy, Higher Education

\section{Introduction}

The popular machinery that resembles a computer and has the portability of a laptop but smaller in size is a cellular phone, which is known as a smartphone. In supporting educational technologies, many students are devoted to their smartphone. A smartphone is one of the technology that has improved massively over past few decade. Smartphone's capabilities and ability to move signals have become increasingly significant, thus, it is perceptible for people to carry and even some own more than one smartphone. The global amount of smartphone users almost attained to two billion in 2016 and is now predicted to exceed that value by 2017 [44]. The exponential rise of smartphone users has made it incontrovertible that people are getting more dependent on this technology that potentially affecting their mannerism in smartphone management especially for students. Though, the development of smartphones has 
given students especially at higher level easy access to the Internet for varied purposes such as education, research, teaching, tutorials, social communications, etc.

However, there is a concern on student's belief to succeed in condition whereas a smartphone can become an educational aids in accomplishing their academic activities. The student belief about their capabilities to produce designated level of performance is referred to student self-efficacy. Self-efficacy is important factor for academic learning, critical thinking, performance and motivation. Students' with smartphone in mobile learning with a strong self-efficacy are more open to new learning approach and experiences [38] at the same time the students are more to new ideas and different learning opportunities [10, 26, 41].

Students are heavily relied on the mobile learning tools and its applications to support daily academic routines [35]. The capability to easily access academic contents through smartphone via Apps and other supporting mobile technologies [45]. It refers to smartphone self-efficacy that extent the ability to enhance educational aids at university level. It will depends on students' self-confident and user characteristics such as internet literacy computer literacy and prior experience and user's smartphone usage and habits. In addition, university environment has adopted varies of approaches to improve students' self-efficacy trough educational technologies of mobile learning such as online discussion, online project collaboration, or interactive multimedia teaching.

Thereby, the study conducted is to collect the responses from students at university and verify the influence of smartphones on their self-efficacy and mobile learning activities. The study is aimed to investigate the relationship between student characteristics of higher level students which determine the use of smartphone in the context of mobile learning. More specifically, the purpose of the study was to identify the relationship between:

- Smartphone habits and self-efficacy

- Self-efficacy and Internet literacy;

- Self-efficacy and mobile learning;

Although this study was conducted in Brunei, the proposed model and finding can be readily used by other researchers in different settings. In the next section, we present a review of related work. This is followed by an outline of the methodology. Next, we present our analysis and findings as well as the discussion. The final section represents the conclusion.

\section{Theoretical Background}

Self-efficacy plays important role in how students feel, behave, and think. Selfefficacy was originated by Bandura [7], it is personal's beliefs in their capabilities to produce desired effect by their own actions. Similarly, self-efficacy as a personal belief that an individual is capable of performing in an appropriate and effective manner to attain certain goals [37]. In this section we highlight on student self-efficacy in supporting mobile learning as educational aids for students at the university level. 


\subsection{Student Self-efficacy}

Student self-efficacy is a construct that was developed within the context of Bandura's social cognitive theory. It is the belief that students have about their abilities and skills as to acquire information and process them into knowledge. Student's selfefficacy has become an important characteristic of the student and one strongly related to success in learning. Self-efficacy beliefs are among the knowledge structures that act as a pervasive influence on personal's successful development especially in academic performance [15]. Students' judgments of their capability to perform academic tasks, that is, their self-efficacy beliefs, predict their capability to accomplish such tasks [8].

Self-efficacy is a self-system that controls most personal activity, including appropriate use of professional knowledge and skills [24]. Since, university life can be demanding and stressful especially for a new student [34] that requires higher levels of independence, initiative, and self-regulation [14]. According to self-efficacy theory, there are four basic information sources of one's self-efficacy: performance accomplishments (i.e. past experiences), vicarious learning (i.e. modelling by others), verbal encouragement (i.e evaluative feedback), and physiological and emotional states [9]. Personal's level of emotional states are influenced on personal belief. Personal belief in a positive consequence of a particular behavior may be more important than the behavior has caused a positive consequence in the past [39]. Therefore, personal belief is only one component of self-efficacy to attain designated types of performances. For instance, a student student's belief and enthusiasm in using smartphone for learning activities can lead learning success because he may have high efficacy rather than students that have low self-efficacy believing smartphone is an interference in learning.

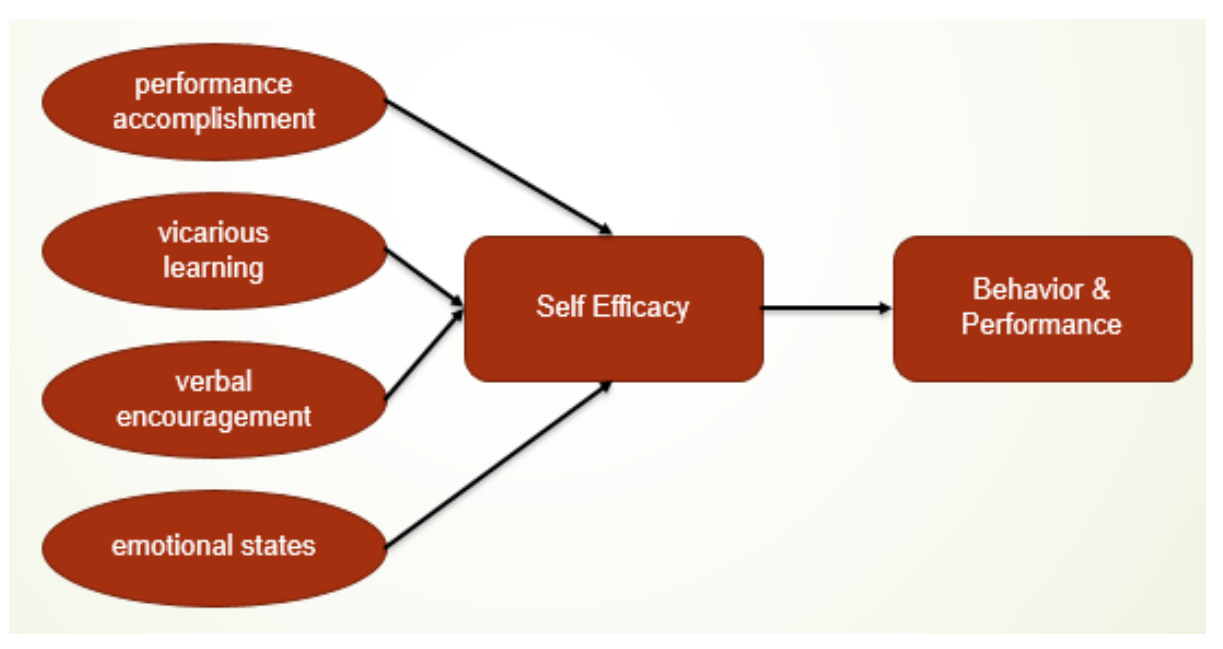

Fig. 1. Components of of Self-Efficacy (Source's: Bandura, 1997) 
Self-efficacy has also been characterized by self-concept, including the terms of self-perception, and self-esteem. Self-perception defines how individuals think about themselves, which expresses the cognitive part of one's self (self-knowledge). Selfesteem generally expresses the emotional part as the evaluation component of selfconcept. As a component of emotional attitude it determines how individuals feel about themselves.

Student self-efficacy is own believe, expectation, confident, or judgment concerning his or her ability to accomplish academic tasks and assessment. It is a personal judgments of own capabilities to perform a specified actions [43] and its beliefs about their ability to do the task [40]. It beliefs influence the particular courses of action a person chooses to pursue, the amount of effort that will be expended, perseverance in the face of challenges and failures, resilience, and the ability to cope with the demands associated with the chosen course [17].

In previous study showed that student self-efficacy was able to improve academic performance in specific cognitive areas was well developed, and it was also very clear that self-efficacy is much more than the reflection of content specific ability [17]. For instance, computer self-efficacy influences expectations and emotional reactions regarding the effective use of ICT $[19,32]$. Thus, people who feel that they are low in computer literacy are less likely to use them [5]. On the other hand, attitudes towards computer are linked also to self-efficacy since they are deemed to be a significant factor in the interpretation of the frequency and success with which individuals use computers $[6,19]$. The study attempts to fill the gap by examining student selfefficacy in regard to smartphone habits and mobile learning.

\subsection{Smartphone Habits and Mobile Learning}

The most important feature of smartphone is communication. The accessibility to the Internet through smartphone has become a daily routine for people to an extent that is over-depended on. With a smartphone, people can communicate without concerning about the distance. Smartphones have been broadly adopted by mainly the youth [16]. Through the advancement made today, they are also used for other purposes such as entertainment, bills payment, audio and camera recording and internet browsing. These smartphones have become an adaption for all age groups, either younger generations or older generations. A study over 140 individuals in Spain, whose ages range between 20 to 60 years old and they found that smartphones are commonly used for their convenience in communication [18]. In Riyadh, a research that has been carried out on 450 individuals, age ranging between 18 to 55 years old [1], reported that smartphones are mostly utilized for their communication purposes and also entertainment purposes. An investigation of smartphones usage in UK, conducted by O'Hara et al (2014) on 20 people (17 to 49 years old), found that smartphones, specifically WhatsApp, is a place where individuals would express their problems to their peers.

Hence, smartphones are likely to become an addiction to both generations and the daily usage of smartphones has been studied by several researchers from other countries [12]. In short, smartphone have ben affecting on the reformation of daily activi- 
ties execution making matters such as learning and working, effortless according to its outlook. With the advanced technology nowadays, it has made the citizen to become more dependent in smartphone. The excessive use of smartphone considered to be a problematic mobile phone use as behavioral addiction such as loss of control, tolerance and withdrawal [11]. Overuse of smartphone brings concerns to users' physical health. Long period of time looking into smartphone cause pressure on spine which is in a long term it becomes pain in neck.

There are majority of aspects that ratify the addiction of smartphone usage such as the type of smartphones used, the distinctive attributes and their gender for instance, the ways of using smartphones vary between males and females [21]. The excessive use of smartphones has resulted in the correspondence of social issues and smartphone addiction [30]. Teenagers spent more time to engage with their friends on a mobile phone especially when the parents are driving. They used the time to textmessage with their friends or update their social networks [13]. Availability of Wi-Fi and cellular data services is rapidly growing which provides many option to stay connected everywhere at any time [35]. In addition, the wide range of applications available in smartphones advocates the habitual urge of staying connected to the Internet [36]. An addicted smartphone user stated that they feel anxious and tense when their smartphones are misplaced and it affects their well-being such as emotions, habits and thoughts [30]. Convenience means to perform task in an uncomplicated way without having to use so much energy. Students use smartphones to get information about anything easily just from the access of the Internet [20].

Smartphone is also applied in education either as a student or educators [31, 33]. With smartphone uses them as a teaching tool, methods and mechanism to spread information fast and easily. While on student perspectives it is definitely a big help to gather information just their fingertip [42]. Students are exposed to different ways of learning through the internet. They can access a lot of variety of information within a short period of time anywhere and anytime making learning a lot easier. ICT in general ICT has a good side in learning [27]. For instance, it saves up so much time in writing by comparing writing an essay on a paper and making one using word application. Writing on paper is tiring, even a single word may take up 3 seconds of the time while on the keyboard its only like 1.5 seconds. Another best thing would be how convenient word application is for highlighting wrong spellings but on paper, we have to proofread, even with chances of missing the wrong spellings which equals to losing marks [4].

Smartphones can be used as recording lectures, which aids in educational teaching and learning in the sense that presentations or lectures can be recorded using a video recorder [25]. The recorded lectures can then be used as a students' guidance as well as reference for their assignments or homework. What the study can revealed that the results students spend more time on the Internet through smartphone. Students also tend to be the more advanced users of smartphones [3]. In terms of activities done using smartphones, students mostly use instant messengers though students are more active on social networking sites and almost of the student sample use it several times for streaming and mobile learning [23]. 
However, even though smartphone connects people through social media but the interaction between people verbally decreases [28]. This affects the students or students-teacher bond where nowadays they spend nearly all of their time alone with mobile phone on their hand. They do not even concern of managing their time to make bond with their teachers or other students [24]. There is an issue of information reliability and quality in mobile learning. Is the information that we have received from this website correct? This is a big issue because due to the amount of information on the internet is vast, there are many information made by someone that could be misleading and false. Self-efficacy and confidence of students should in line with literacy level in using and sharing only reliable information [22].

\section{Method}

The study concerns the assessment of university students' characteristics of smartphone habits and how these characteristics affect the integration of mobile learning. A total of 1000 questionnaires were distributed both electronically and manually. The participants were 847 of university students from all academics majoring. The participants varies from undergraduate to postgraduate studies. The study was conducted in Brunei Darussalam, a country located on the island of Borneo and consists of four districts. The population of Brunei Darussalam is 348,200 comprising 53 percent men and 47 percent women, with $73.8 \%$ Malay, $14.8 \%$ Chinese, and $11.4 \%$ other ethnicities (AITI 2010). They were selected via the simple random sampling method in order to complete the questionnaire regarding the demographic questions and selfevaluation questionnaires. The purpose of the study was to investigate the relationship between smartphone habits amongst students at higher level institution and selfefficacy. Specifically the study investigated the following questions:

1. The relationship between self-efficacy and Internet literacy.

2. The relationship between self-efficacy and smartphone habits.

3. The relationship between self-efficacy and mobile learning activities.

The research instruments for the data collection were:

i) The questionnaire of students' demographic.

ii) The questionnaire of Internet usage and smartphone's activities.

iii) The questionnaire of mobile learning through smartphone.

iv) The questionnaire of smartphone's habits.

v) The self-efficacy scale. It includes 4 items that are usually scored using a three point response ranging agree, neutral, and disagree.

The survey was carried out on February 22nd to March 1st, 2015. All the data were analyzed using SPSS version 17.0. Data were analyzed to find out the descriptive analysis of subject matter and correlation between variables. The theory, concepts, and findings were then used to obtain an understanding of the phenomenon and as a basis for providing recommendations. 


\section{$3 \quad$ Findings}

For the analysis of self-efficacy and university's student characteristics that determine numbers of hours spent on computer or smartphone and level of in Internet literacy. Table 1 indicated the mean, the standard deviation and correlation significance ( $p$-value) for student characteristic and self-efficacy. Positive correlation between self-efficacy and students' internet literacy as well as hours of spent on smartphone. Hours spent on smartphone and internet literacy provide students a sense of confidence, accomplishment when they face a challenge or a new exposure of experience including mobile learning activities.

Table 1. Average, mean difference of Internet Literacy and self-efficacy

\begin{tabular}{|l|c|c|c|c|c|}
\hline \multicolumn{1}{|c|}{ Variable } & $\boldsymbol{N}$ & Scale max. & Mean & s.d. & self-efficacy \\
\cline { 4 - 6 } & & & & $\boldsymbol{p}$ \\
\hline $\begin{array}{l}\text { Number of hours spent on computer } \\
\text { or smartphone }\end{array}$ & 857 & 3 & 2.01 & 0.699 & 0.026 \\
\hline Internet Literacy & 857 & 4 & 2.36 & 0.751 & 0.050 \\
\hline
\end{tabular}

$\mathrm{n}=$ sample size $; \mathrm{p}=$ statistical significance of correlation; $\mathrm{p}<0.05$.

Furthermore, each student has a different priorities and preferences in utilizing their smartphone usage which could have an impact in supporting mobile learning. Table 2 shows the results of the collaboration between self-efficacy and smartphone habits. Multiple variable analysis was used in analyzing self-efficacy and smartphone activities. The excessive use of smartphone, according to the study are mostly used for instant messaging, social networks and moderate level for mobile learning (Figure 2 ). The analysis shows that there is correlation between those activities and students self-efficacy. The personal feelings of the participants are mostly consistent. Another fact of smartphone addiction is the high rate of people checking their smartphone with no reason even at transport, restaurant, even restroom and claiming that they cannot live without their smartphones.

Table 3 indicates positive experiences with mobile learning will increase the feeling to succeed. We found inherent correlations of students' self-efficacy that helps in understanding how university students use their smartphone for mobile learning. Furthermore, we established that participants from agreed that they cannot live without their smartphone, and they have a tendency to use their smartphones in restaurants and at home.

Figure 2 shows that the ever-growing habits and usage on smartphones can be indicated by the amount of time for university students spend on their smartphones, the usage for social networking (SNS), instant messaging like WhatsApp, mobile news, mobile streaming, mobile commerce, and mobile learning. 
Table 2. Correlation between self-efficacy and smartphone activities or habits

\begin{tabular}{|l|c|c|c|c|c|}
\hline \multicolumn{1}{|c|}{ Variable } & n & Scale max. & Mean & s.d. & Self-efficacy \\
\cline { 5 - 6 } & & & & & $\boldsymbol{p}$ \\
\hline Social networks & 857 & 4 & 1.74 & 0.741 & 0.048 \\
\hline Instant messaging & 857 & 4 & 1.21 & 0.485 & 0.028 \\
\hline Gaming & 857 & 4 & 2.762 & 1.054 & 0.039 \\
\hline Video streaming & 857 & 4 & 1.870 & 0.816 & 0.015 \\
\hline Smartphone at transport & 857 & 3 & 2.114 & 0.814 & 0.003 \\
\hline Smartphone at restaurant & 857 & 3 & 1.685 & 0.696 & 0.020 \\
\hline Smartphone at restroom & 857 & 3 & 1.697 & 0.723 & 0.091 \\
\hline
\end{tabular}

$\mathrm{n}=$ sample size; $\mathrm{p}=$ statistical significance of correlation; $\mathrm{p}<0.05$.

Table 3. Correlation between self-efficacy and mobile learning activities

\begin{tabular}{|l|c|c|c|c|c|}
\hline \multicolumn{1}{|c|}{ Variable } & $\boldsymbol{n}$ & Scale max. & Mean & s.d. & Self-efficacy \\
\cline { 3 - 6 } & 857 & 4 & 2.454 & 0.968 & 0.029 \\
\hline mLearning Apps & 857 & 4 & 2.224 & 0.944 & 0.007 \\
\hline $\begin{array}{l}\text { Smartphone at } \\
\text { class/lecture/tutorial }\end{array}$ & 857 & 3 & 1.962 & 0.677 & 0.010 \\
\hline $\begin{array}{l}\text { Smartphone improve my } \\
\text { academic work }\end{array}$ & & & & & \\
\hline
\end{tabular}

$\mathrm{n}=$ sample size $; \mathrm{p}=$ statistical significance of correlation; $\mathrm{p}<0.05$.

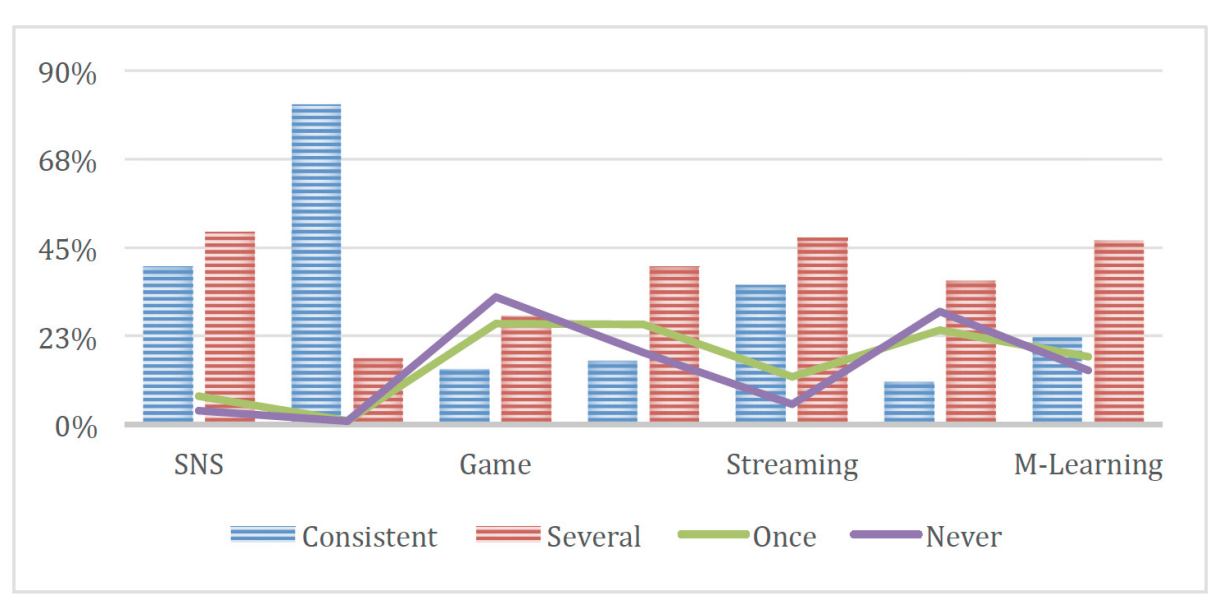

Fig. 2. Higher Learning Students on Smartphone Activities (Source: Authors' compilation) 


\section{Discussion}

According to Bandura's theory, four sources of students' efficacy in the context of mobile learning the findings are performance accomplishment, vicarious experience, social persuasion, and Physiological and Emotional State. Performance accomplishment is shown from mastery smartphone experience. The study shows situations in which students demonstrate their own smartphone experiences from the excessive use of smartphone habits (Figure $2 \&$ Table 2) and high Internet literacy's level (Table 1), thus proving that students are mastery smartphone users. Mastery smartphone experiences are the most influential source of self-efficacy information because indicating the reliable evidence of whether student to succeed in mobile learning experience. Success builds a robust belief in personal efficacy [7]. Vicarious Experience in mobile learning is obtained from observation or experience of others than own direct experience. Successful mobile learning experiences and observation through Canvas Instructure from respondents (Figure 1) generate confidences of students can learn from successes of other students, resulting their positive self-efficacy (Table 3). Students learn to be effective in mobile learning by modelling the habits (i.e smartphone habits) of other students being effective. Social Persuasion by facilitators and teachers that a student receives a positive feedback of any mobile learning activities will develop student self-efficacy. For instance, providing motivation and encouraging comments through mobile learning platform will affect student self-efficacy positively. Essentially, moral support builds a student's confident in self-efficacy relating to mobile learning approach. While, emotional states and physiological of each student influence self-efficacy judgments. For example, a student's enthusiasm for mobile learning can provide signal about anticipated mobile learning success. On the other hand, feeling of anxiety, stress, burdens, and other negative conditions can lead to negative judgments of students' capabilities and skills in getting value-added of mobile learning activities. Therefore, it differentiates between students self-efficacy from students self-confidence. A student could have high internet literacy may not be a successful if student negative emotional state come into play. In detail, we discuss of students self-efficacy in mobile learning at Figure 3.

\subsection{Self-efficacy \& Internet Literacy}

Self-efficacy relates to belief about students ability to effectively perform required tasks to gain the value. The study reveals that self-efficacy has correlation with internet literacy simply because internet literacy level shows how confident students are in doing certain activities like mobile learning. It is evident that the reliant to smartphones will increase overtime since smartphones have easy access to the Internet [45]. Students use more online research because the Internet provides variety of information instantly, anytime and anywhere. Students gain more information online than offline and benefit more from online research and learning activities [2], as there are also the electronic versions of physical books available on the Internet. The study emphasis was on aspects of self-efficacy and time spent using smartphone for supporting mobile learning. Student's self-efficacy in the context of mobile learning is an 
ability to succeed in accomplishing mobile learning activities by utilizing smartphone as learning aids. From the analysis above, students are active users of smartphones and they use it daily for various activities (Figure 2).

As shown at Table 1 that there is correlation between Internets literacy level of student and self-efficacy. Therefore, students with a greater level of internet literacy and self-efficacy tend to prefer educational technologies based on mobile learning as a platform of learning activities, whereas students with lower internet literacy and self-efficacy prefer more traditional learning methods such as face to face interaction, library research, or traditional lectures. It is supported by Looney, Valacich, \& Akbulut (2004) that self-efficacy reflects considerable positive influence regarding technology self-efficacy that improves a significant level in the use and development of online research. Students feel that smartphone could improve their learning by enhance literacy skills such as post homework problems, practice exams, discussion group, live chat room, share files through email, etc. Internet literacy gives motivation effect which increase the learning interest. Student can do their research that has many more resources without having to go to the library. Self-efficacy helps students to not only rely on what the lecturer has given them but multi channels of knowledge resources are available. It confirms the study that there is relationship between internet literacy and the level of self-efficacy of students. With a few clicks of the keys on a smartphone, any answer to any question can basically be established. Powerful search engines provide a simpler and structured way to find the information that the students may need for their assignments or projects [45].

\subsection{Self-efficacy \& Smartphone Habit}

The construct of self-efficacy has empirical attention with the smartphone habit in the context of mobile learning. Smartphone habit can improve students in general and students with disabilities in the learning process. The smartphone habits help beneficially students especially with disabilities to confidently engage and communicate towards other students and tutors with less barriers as a way for them to understand information easier. Regardless of the advantages of mobile learning, there are also some disadvantages of using it. An excessive use of smartphone including for mobile learning activities can impact to smartphone's addiction lead to anxiety, stress, and dependency. The overuse of smartphones can lead to addiction and disability to manage time wisely. The rise of the term "phubbing", a combination of the word "phone" and "snub", is caused by the growing numbers of students that seems to always be on their smartphone and ignoring the people around them. This affects their social skills, affecting their studies. Hence, awareness of moderate usage of smartphones should be initiated even though the designation of mobile learning is to make life easier. Apart from that, smartphone habits can interference learning activities in a way that student misuse smartphone where they are busy focusing on social networking site or playing games. Therefore, smartphone habit could reduce listening skills in the learning activities. Attentiveness can drop drastically in class when students have their smartphone. Their focus might shift from the lecture, to whatever they are doing on these gadgets. Students believe that smartphone can be an interference due to the existence of social 
networking sites. They believe that social networking sites and instant messengers like WhatsApp can become a source of distraction and procrastination. The use of smartphone in learning can be a struggle in a way that there is a challenge of multitasking. The probability to switch back and forth between tasks really quickly does exist, thus conflict our minds to stay focused and make distractions significantly easier.

\subsection{Self-efficacy \& Mobile Learning}

We cannot deny that smartphones are useful to people and it has been imbedded into their daily life. The main intention of mobile learning is for easier long distance learning with friends, teachers and even communities. Additionally, access to the Internet has never been easier and the vast amount of information is just at the tip of our fingers. Furthermore, there are mobile learning applications for almost supporting all modules of distance learning activities. Besides for communication, smartphones in mobile learning can also function as a video recorder to record lectures. There are many characteristics of higher learning students that may consider having selfefficacy in using mobile learning as educational aid.

There are many points of mobile interactions can happen through smartphone in helping students to improve their confident and understanding about a mobile learning not only from because of internal factors but also external forces. Figure 3 shows selfefficacy in mobile learning that offers a better way to increase student participation, confidence as well as engagement in the learning process is to be available to students beyond classroom interaction. People tend to be self-referent beliefs that are proactive and self-regulating rather than as reactive and controlled by biological or environmental forces [9]. Therefore, there are internal forces affect to student's self-efficacy such as feeling confidence, personal belief and habits, individual literacy, and conciseness. The higher internal forces for self-efficacy is the more student can utilize mobile learning which in turn will result to performance, accomplishment, and new experiences of using smartphone for educational aids.

Self-efficacy can improve also due to external forces such as rule or regulations from university to implement Learning Management Systems (LMS), promotion or marketing [45], and friends or families. Smartphones can successfully be used for mobile learning by using it to find for an answer from the Internet, submit assignments to lecturer via e-mail or LMS's platforms such as Canvas or Edmodo and organize all of students' works in a folder so works will be easier to find and then use it as a reference. Learning through smartphones can extend beyond the walls of a classroom or the confines of a class period. Students can easily share information with peers or lecturers. They are notified when something is posted on LMS's platforms and can easily come back and view what was being posted on their free time [45].

Furthermore, external and internal forces influence vicarious experience in student self-efficacy by modelling others do a task. Students with positive vicarious experiences in mobile learning will express more acceptance of mobile learning as educational aids. Conversely, students with negative vicarious experiences have more low attitudes towards mobile learning which in turn resulting smartphone as interference 
in mobile learning (Figure 3). In term of social persuasion, a positive verbal feedbacks from external forces will impact to internal forces of feeling being encouraged and convinced to perform a task. Students tends to believe that they are capable of accomplishing mobile learning task. Positive feedback is important to improve sense of selfefficacy as it may help confidence of mobile learning as educational aids.

Whenever students participate mobile learning, they interpret their performance, accomplishment and experiences to develop beliefs about their ability to engage in similar activities. If these activities are consistently successful, they tend to raise selfefficacy or, conversely, if these activities typically produce failure, self-efficacy is likely to be lowered. Therefore, if a student originally has a low sense of efficacy, it will bring doubt about his abilities. Such doubt likely will result in failure in mobile learning scenario, and also reinforce low self-efficacy.

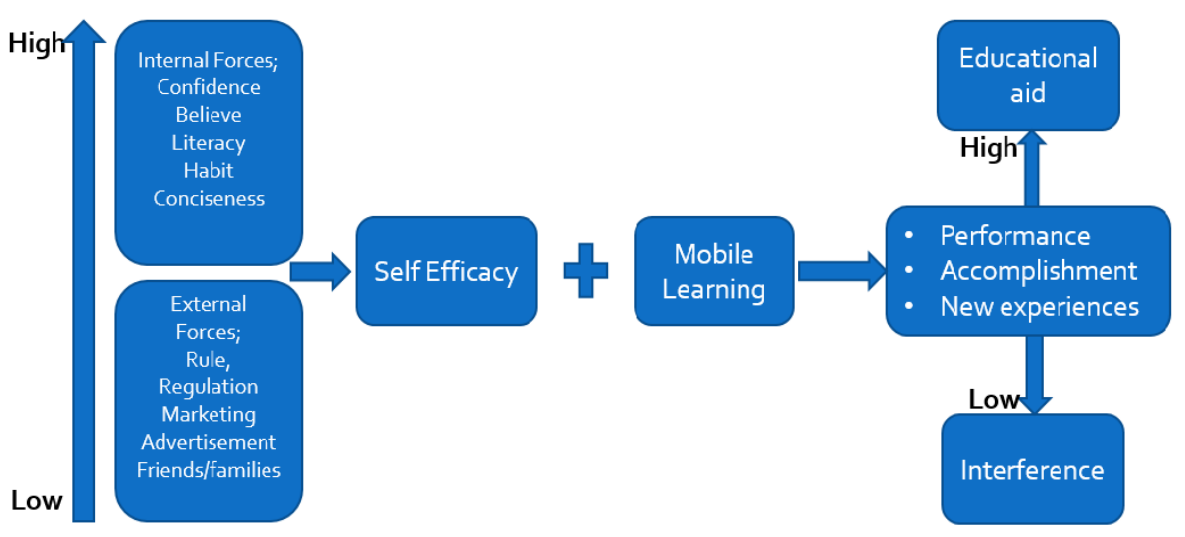

Fig. 3. Self efficacy in mobile learning (Source: Authors' compilation)

In addition, a low level of internal forces may result of smartphone as interferences for academics' achievement. The students may use it for other entertainments during the lessons and plagiarism could increase in numbers. In addition, not all mobile learning are valid and reliable. It need people with qualification in mentoring and facilitating of quality assurance in the online learning scenario.

\section{Conclusions}

A number of general conclusions can be drawn from this study. Different setting of demographic may lead to different experiences of students which in turn different level of self-efficacy either positive or negative outcome for higher learning students. According to a study, there is a significant convergent between the exponential use of smartphones and an academic activities especially mobile learning. There are points of smartphone in helping students to improve their confident and understanding about a mobile learning not only from because of internal factors but also external forces. Whenever students participate mobile learning, they will interpret their performance, 
accomplishment and experiences to develop beliefs about their ability to engage in similar activities. While, similar activities are bounded with the smartphone habits and internet literacy level. If these activities are consistently successful, they tend to raise self-efficacy or, conversely, if these activities produce failure then it leads to low self-efficacy.

\section{References}

[1] Alosaimi, F. D., Alyahya, H., Alshahwan, H., Al Mahyijari, N., \& Shaik, S. A. (2016). Smartphone addiction among university students in Riyadh, Saudi Arabia. Saudi medical journal, 37(6), 675-683. https://doi.org/10.15537/smj.2016.6.14430

[2] Anderson, T. (2008). The theory and practice of online learning. Athabasca University Press.

[3] Anshari, M., et.al. (2017). Smartphones usage in the classrooms: Learning aid or interference?. Education and Information Technologies. https://doi.org/10.1007/s10639-017-9572-

[4] Anshari, M., \& Alas, Y. (2015). Smartphones Habits, Necessities, and Big Data Challenges. The Journal of High Technology Management Research. 26 (2): 177-185. Elsevier, https://doi.org/10.1016/j.hitech.2015.09.005

[5] Anshari, M., Alas, Y., \& Guan, L. S. (2016). Developing online learning resources: Big data, social networks, and cloud computing to support pervasive knowledge. Education and Information Technologies, Springer 1-15. https://doi.org/10.1007/s10639-015-9407-3

[6] Anshari, M. \& Lim, S.A. (2017) E-Government with Big Data Enabled through Smartphone for Public Services: Possibilities and Challenges, International Journal of Public Administration, 40:13, 1143-1158, https://doi.org/10.1080/01900692.2016.1242619

[7] Bandura, A. (1997). Self-efficacy: The exercise of control. New York: Freeman.

[8] Bandura, A. (1984). Recycling misconceptions of perceived self-efficacy. Cognitive Therapy and Research, 8, 231-255. https://doi.org/10.1007/BF01172995

[9] Bandura, A. (1986). Social foundations of thought and action: A social cognitive theory. Englewood Cliffs, NJ: Prentice Hall.

[10] Benson, S. (2004). Computer anxiety: Impediment to technology integration? http://pt3.nmsu.edu/research/Benson.html.

[11] Billieux, J., Maurage, P., Lopez-Fernandez, O., Kuss, D. J., \& Griffiths, M. D. (2015). Can disordered mobile phone use be considered a behavioral addiction? An update on current evidence and a comprehensive model for future research. Current Addiction Reports, 2(2), 156-162. https://doi.org/10.1007/s40429-015-0054-y

[12] Boulos, M.N.K, Wheeler, S., Tavares, C. and Jones, R. (2011). How smartphones are changing the face of mobile and participatory healthcare: an overview, with example from eCAALYX. BioMedical Engineering OnLine. https://doi.org/10.1186/1475-925X-10-24

[13] Bilton. N. (2011), Disruptions: For teenagers, a Car or a Smartphone? [article]. Retrieved from: $\quad$ http://bits.blogs.nytimes.com/2011/11/20/a-teenage-question-a-car-or-asmartphone/?_r=0

[14] Bryde, J. F., \& Milburn, C. M. (1990). Helping to make the transition from high school to college. In R. L. Emans (Ed.), Understanding undergraduate education (pp. 203-213). Vermillion, SD: University of South Dakota Press.

[15] Caprara, G. V., Barbaranelli, C., Pastorelli, C., \& Cervone, D. (2004). The contribution of self-referent beliefs to personality development. Perceived self-efficacy and Big Five con- 
structs as predictors of psychosocial outcomes. Personality and Individual differences, 37, 751-763. https://doi.org/10.1016/j.paid.2003.11.003

[16] Carroll, J., Howard, S., Vetere, F., Peck, J., \& Murphy, J. (2002). Just what do the youth of today want? Technology appropriation by young people. In System Sciences, 2002. HICSS. Proceedings of the 35th Annual Hawaii International Conference on (pp. 17771785). IEEE. https://doi.org/10.1109/HICSS.2002.994089

[17] Chemers, M. M., Hu, L. T., \& Garcia, B. F. (2001). Academic self-efficacy and first year college student performance and adjustment. Journal of Educational psychology, 93(1), 55. https://doi.org/10.1037/0022-0663.93.1.55

[18] Church, K., \& de Oliveira, R. (2013, August). What's up with whatsapp?: comparing mobile instant messaging behaviors with traditional SMS. In Proceedings of the 15th international conference on Human-computer interaction with mobile devices and services (pp. 352-361). ACM. https://doi.org/10.1145/2493190.2493225

[19] Compeau, D., \& Higgins, C. (1995). Computer self-efficacy: Development of a measure and initial test. http://www.misq.org.

[20] Davies, J., \& Graff, M. (2005). Performance in e-learning: online participation and student grades. British Journal of Educational Technology, 36(4), 657-663. https://doi.org/10.1111/j.1467-8535.2005.00542.x

[21] Deursen, A. J. A. M. V., Bolle, C. L., Hegner, S. M., \& Kommers, P. A. M. (2015). Modeling habitual and addictive smartphone behavior: The role of smartphone usage types, emotional intelligence, social stress, self-regulation, age, and gender. Computers in Human Behavior, 45, 411-420.

[22] Ferrándiz, E., Puentes, C., Moreno, P. J., \& Flores, E. (2016). Engaging and assessing students through their electronic devices and real time quizzes. Multidisciplinary Journal for Education, Social and Technological Sciences, 3(2), 173-184. https://doi.org/10.4995/ muse.2016.6375

[23] Garcia, E., Elbeltagi, I. M., Dungay, K., \& Hardaker, G. (2015). Student use of Facebook for informal learning and peer support. The International Journal of Information and Learning Technology, 32(5), 286-299. https://doi.org/10.1108/IJILT-09-2015-0024

[24] Gavora, P. (2010). Slovak pre-service teacher self-efficacy: Theoretical and research considerations. The New Educational Review, 21(2), 17-30.

[25] Gromik, N. A. (2016). The effect of theme preference on academic word list use: A case for smartphone video recording feature. Education and Information Technologies, 1-15.

[26] Hsioung, Yu-Lu. (2002). Preservice teacher preparation to integrate technology and mathematics. Review of Literature.

[27] Jacob, S., \& Radhai, S. (2016). Trends in ICT E-learning: Challenges and Expectations. International Journal of Innovative Research and Development|| ISSN 2278-0211, 5(2).

[28] Kim, J. H. (2017). Smartphone-mediated communication vs. face-to-face interaction: Two routes to social support and problematic use of smartphone. Computers in Human Behavior, 67, 282-291. https://doi.org/10.1016/j.chb.2016.11.004

[29] Lee, Y. K., Chang, C. T., Lin, Y., \& Cheng, Z. H. (2014). The dark side of smartphone usage: Psychological traits, compulsive behavior and technostress. Computers in Human Behavior, 31, 373-383. https://doi.org/10.1016/j.chb.2013.10.047

[30] Lee, J., Cho, B., Kim, Y., \& Noh. (2015). Smartphone addiction in university students and its implication for learning. Retrieved from http://link.springer.com/chapter/10.1007/9783-662-44188-6_40\#page-3 https://doi.org/10.1007/978-3-662-44188-6 40

[31] Lindberg, J. O., Olofsson, A. D., \& Fransson, G. (2016). CONTRASTING VIEWS: STUDENT AND TEACHER PERCEPTIONS ON ICT IN EDUCATION. In ICICTE 
2016, International Conference on Information and Communication Technologies in Education, Rhodes, Greece, 7-9 July, 2016 (pp. 1-10).

[32] Looney, C., Valacich, J., \& Akbulut, A. (2004). Online investment self-efficacy: Development and initial test of an instrument to assess perceived online investing abilities. In Proceedings of the 37th Hawaii international conference on system sciences. http://csdl2.computer.org/comp/proceedings/hicss/2004/2056/07/205670184b.pdf.

[33] Nalwa, K., \& Anand, A. P. (2003). Internet addiction in students: A cause of concern. CyberPsychology \& Behavior, 6(6), 653-656. https://doi.org/10.1089/109493103322725441

[34] Noel, L., Levitz, R., \& Saluri, D. (1985). Increasing student retention: Effective programs and practices for reducing dropout rate. San Francisco, CA: Jossey-Bass

[35] Novo-Corti, I., Pociovalisteanu, D. M., \& Iorgulescu, R. I. (2015). Social Sustainability In Higher Education. The Role Of Institutions From Students' Point Of View. Journal for Economic Forecasting, (3), 166-180.

[36] Okazaki, S., \& Hirose, M. (2009). Does gender affect media choice in travel information search? On the use of mobile Internet. Tourism Management, 30(6), 794-804. https://doi.org/10.1016/j.tourman.2008.12.012

[37] Ormrod, J. E. (2006). Educational Psychology: Developing Learners (5th ed.), glossary. N.J., Merrill: Upper Saddle River

[38] Paraskeva, F., Bouta, H., \& Papagianni, A. (2008). Individual characteristics and computer self-efficacy in secondary education teachers to integrate technology in educational practice. Computers \& Education, 50(3), 1084-1091. https://doi.org/10.1016/j.comp edu.2006.10.006

[39] Paixão, M. P., \& Panahandeh, A. (2017). Predicting of Academic Performance by Identity Styles and Self-efficacy Beliefs (Personal and Collective) in Iranian High School Students. World Scientific News, 61(2), 186-191.

[40] Pintrich, P. R. (2003). A motivational science perspective on the role of student motivation in learning and teaching contexts. Journal of educational Psychology, 95(4), 667. https://doi.org/10.1037/0022-0663.95.4.667

[41] Roussos, P. (2002). Computer attitude correlates: Do they tell us anything new? http://psychology.uindy.gr/ICTE_paper_Roussos.pdf.

[42] Samaha, M., \& Hawi, N. S. (2016). Relationships among smartphone addiction, stress, academic performance, and satisfaction with life. Computers in Human Behavior, 57, 321325. https://doi.org/10.1016/j.chb.2015.12.045

[43] Schunk, D. H. (1991). Self-efficacy and academic motivation. Educational psychologist, 26(3-4), 207-231. https://doi.org/10.1080/00461520.1991.9653133

[44] Statista, (2017). Number of smartphone users worldwide from 2014 to 2020 (in billions). Retreived January 31, 2017 from https:/www.statista.com/statistics/330695/number-ofsmartphone-users-worldwide/.

[45] Wu, J. H., Wang, Y. M., \& Tai, W. C. (2004). Mobile shopping site selection: The consumers' viewpoint. In System sciences, 2004. Proceedings of the 37th annual Hawaii international conference on (p. 8). IEEE.

\section{$7 \quad$ Authors}

Abdur Razzaq is member of the researcher association at South Sumatra and member of Islamic Economic Expertise. He is lecturer at Faculty of Dakwah and Communication Universitas Islam Negeri Raden Fatah Palembang Sumatera Selatan Indonesia. 
Yulia Tri Samiha is active researcher in the field of education at higher learning institution and involve as advisor at Small Medium Enterprise Develeopment for Muslim women at South Sumatra. She is lecturer at Faculty of Education Universitas Islam Negeri Raden Fatah Palembang Sumatera Selatan Indonesia.

Muhammad Anshari is researcher and Assistant Professor Management Information System. His professional experience started when he was IT Business Analyst at Astra International, Research Fellowship from Government Republic of China (Taiwan) at National Taiwan University (Jan-Dec, 2014). Research Fellowship from King Saud University The Kingdom of Saudi Arabia 2009. Best Paper and Presenter Award International Conference on ASEAN Studies 2 (ICONAS2) at Chulalongkorn University Bangkok Thailand 2015. Best Paper and Presenter Award, ASEAN Graduate Business Economic Programs Doctoral Colloquium April 2013, at Gadjah Mada University Indonesia.

Article submitted 11 September 2017. Resubmitted 30 November 2017. Final acceptance 06 February 2018. Final version published as submitted by the authors. 